\title{
Maximal oxygen uptake and concentric isokinetic muscle strength in pubertal football trained and untrained boys of the same biological age
}

\author{
Athanasios Mandroukas*, Jan Heller
}

Faculty of Physical Education and Sport, Charles University, Prague, Czech Republic

* Corresponding author: thanmandrou@hotmail.com

\begin{abstract}
The purpose of the present study was to examine the effects of long term (prolonged) football training on maximal oxygen uptake ( $\mathrm{V}_{2}$ ) and isokinetic muscle strength in young football players and untrained boys of the same biological age. Twenty football competitive boys (mean age $14 \pm 0 \mathrm{yrs}$; height $165.5 \pm 8.5 \mathrm{~cm}$; weight $59.9 \pm 9.5 \mathrm{~kg}$; years of training $7 \pm 3$ ) and eighteen untrained school boys (mean age $14 \pm 0$; height $168.22 \pm 10.46 \mathrm{~cm}$; weight $59.3 \pm 9.9 \mathrm{~kg}$ ) of the same biological age volunteered to participate in the study. Sexual maturation classified according to Tanner's stage 3 . The football players participated both in their school's physical education program and in their football team training program while the untrained group participated only in their school's physical education program (2-3 times per week for $40 \mathrm{~min}$ ). All subjects were tested for maximal oxygen uptake ( $\left(\mathrm{V}_{2}\right)$ and respiratory exchange ratio (RER) on the treadmill using an open circuit spirometry. The isokinetic peak torque values of quadriceps (Q) and hamstrings $(H)$ as well as the $H: Q$ strength ratios were recorded. $H_{\text {con }}: Q_{\text {con }}$ was calculated as the ratio of the peak concentric torque of $H$ to the peak concentric torque of the $Q$. Results showed that the trained group had significantly lower heart rate in rest $(p<0.001)$, higher $\operatorname{RER}(p<0.001)$, maximal blood lactate $\left(\mathrm{BL}_{\max }\right)(\mathrm{p}<0.001)$ and higher $\left(\mathrm{V}_{2}\right)$ max in both relative and absolute values $(\mathrm{p}<0.001)$ compared to the untrained group. At angular velocities of $60^{\circ} \mathrm{s}^{-1}$ and $180^{\circ} \mathrm{s}^{-1}$ the relative peak torque of $\mathrm{Q}$ and $\mathrm{H}$ were significantly higher $(Q=p<0.01 ; H=p<0.01)$. However, the absolute values of $Q$ and $H$ as well as the $H: Q$ ratios at all angular velocities did not differ significantly between the two groups. The results suggest that systematic football training (intensity and duration) has a positive effect in metabolic capacity, cardiorespiratory system and neuromuscular function.
\end{abstract}

\section{KEYWORDS}

muscle strength; hamstrings; quadriceps; $\mathrm{H}$ : $\mathrm{Q}$ strength ratio; biological age; football players; puberty; maximal oxygen uptake

DOI

10.14712/23366052.2019.3

(c) 2019 The Authors. This is an open-access article distributed under the terms of the Creative Commons Attribution License (http://creativecommons.org/licenses/by/4.0), which permits unrestricted use, distribution, and reproduction in any medium, provided the original author and source are credited. 


\section{INTRODUCTION}

Today, children start serious athletic training at earlier ages than ever before. Both in young and adults, football is one of the most popular team sports in the world. It is commonly accepted that the physical activities of football have a positive impact in spiritual, psychological and bodily health (Hagger et al., 2001) and contributes to the maintenance of a physically active lifestyle (Krustrup et al., 2010). Regular football training, two to three times a week, caused significant cardiovascular and muscular adaptation (Nadeau et al., 2011; Krustrup et al., 2010). The aerobic capacity and the muscle strength in prepubertal and pubertal children have been a matter of long-lasting controversy (Vamvakoudis et al., 2007). Some studies demonstrated an improvement inVO ${ }_{2}$ (Eriksson \& Koch, 1973; Máček et al., 1976; Lussier \& Buskirk, 1977; Savage et al., 1986; Baxter-Jones et al., 1993), while other investigations (Kobayashi et al., 1978; Bar-Or, 1983; Mirwald \& Bailey, 1984; Williams \& Reilly, 2000) have shown little or no improvement. During puberty (13-16 years of age) occur difference in body size, aerobic power, muscle strength and performance between boys of contrasting maturity status, e.g. early versus late maturity of the same age (Malina et al., 2004). Complicating factors in this controversy has been mainly the different experimental design of the studies in this area as well as the chronological ages of the subjects (Armstrong, 1997). Most of these studies have been cross-sectional and therefore the effects of growth, development and heredity aspects may have been greater than those brought about by training (Mirwald et al., 1981; Vamvakoudis et al., 2001).

Training during childhood (prepubertal - pubertal) continues to be a subject of interest. However the results of training with children of different chronological age are difficult to separate the effects of training from these of growth. Although the isokinetic muscle strength as well as the aerobic power has been studied extensively there is no information on these variables throughout the same biological age in trained and in normal untrained children who had only the physical activities in the school. More specifically, little is known about the alteration that may occur in $\mathrm{VO}_{2 \max }$ and muscle strength in trained and untrained children. To our knowledge the present study is the first to provide information about the aerobic power and concentric isokinetic strength of knee extensors and flexors in trained and untrained (non-athletic) boys of the same biological age. Thus, the purpose of this study was to examine and compare the difference in aerobic power and isokinetic concentric peak torque of the knee flexor and knee extensor muscles as well as the ratios between already trained and untrained pubertal boys of the same biological age.

\section{MATERIALS AND METHODS}

\section{Participants}

A total of thirty eight (mean $\pm \mathrm{SD}, \mathrm{N}=38,20$ football players and 18 untrained boys, age $=14 \pm 0$ ) subjects volunteered to participate in this study. The participants were divided into two groups: a) football players as trained group, b) untrained boys. The physical characteristics of the subjects are shown in Table 1. All subjects and their parents were informed of the nature, purpose, and the possible risks involved in the study before giving their voluntary written consent for participation. All subjects 
completed a questionnaire that included their relevant medical and physical history. The exclusion criteria were: recent history of muscle injury of the lower limbs, present complaint of thigh and leg pain and any other medical problems contraindicated for experimental testing. Also, overweight boys were excluded from the untrained group. None of the subjects had been doing progressive resistive exercise 24 hours before the testing. All players in the study came from three football academies (clubs) which followed a specific training program, while the untrained came from four different schools of the same region (area). The untrained group participated only in their normal physical education program in their school and did not take part in any other sport activities. The trained group participated both in their schools physical education program and in the national championship competition games. They were a highly selective group with regard to skills, performance, size, anthropometric characteristics and physical condition. Boys of both groups were born on the first 6 months of the same year. Pubertal staging, by examination of pubic hair, penile and testicular development was performed by an experience paediatric physician, experienced in the assessment of secondary sex characteristics, state of pubic hair based on the criteria of Tanner (1962). So, the classification for the sexual maturity for both groups were in Tanner stage three. The participants visited the laboratory in order to be informed about the experimental procedures and familiarised with equipment. Leg dominance was determined by asking the boys the limb that they preferred to use when they kick the ball. The height and body weight were measured using an electronic digital scale (Seca 220e, Hamburg, Germany). Resting heart rate (HR) and resting systolic and diastolic blood pressures (sBP, dBP) were recorded before the testing. Tests were performed in a temperature - controlled laboratory $\left(20^{\circ} \mathrm{C}\right.$ to $21{ }^{\circ} \mathrm{C} ; \sim 50 \%$ relative humidity). The study was performed in accordance with the local university Ethics Committee guidelines and ethical standards of the Sports Medicine research.

\section{Football training program}

The football training protocol focused on the development of technical and tactical skills and on the improvement of game - related fitness. The duration of the training season was 41 weeks per year. They participated in 3 to 4 training sessions of $90 \mathrm{~min}$ each, per week for at least 7 years. Also, they competed in 1 game per week throughout the season. More specifically football training consisted of jogging, stretching, and callisthenics of approximately $45-50 \%$ of the maximal heart rate, followed by alternating $75-85 \%$ for 5-8 minutes and light $50-65 \%$ for $40-45$ minutes. This period included running with and without the ball. Also, jumping and sprinting exercises were a regular part of their practice. The intensity of the session registered by telemetry (Sport Tester, Finland).

\section{Untrained group}

The school physical education program consisted of 2-3 training sessions per week and every session was lasted for 40 minutes. The content of this program consisted of ball games (e.g. football, basketball, volleyball, handball and some calisthenics). The intensity was estimated by telemetry (Sport Tester, Finland). Both the duration and the intensity of the training in this group were much less than the specific training 
program of the football players. Subjects reported no musculoskeletal injuries of the lower limbs that would affects them from performing maximal isokinetic contraction.

\section{Measurement of the isokinetic strength}

Prior to testing, each subject underwent a 5-minute warm-up period on a bicycle ergometer (Monark, Varberg, Sweden) followed by 5 minute of stretching of the hamstrings and quadriceps as previous described by Mandroukas et al. (2014). The subject was then seated on the dynamometer in an adjustable chair; the upper body was stabilised with straps secured diagonally across the chest and the hips. Prior to maximal testing a series of submaximal concentric contractions were performed. Maximal isokinetic strength was recorded as the torque of the quadriceps and hamstrings muscles throughout the whole range of motion, at angular velocities of 60,180 , $300^{\circ} \mathrm{s}^{-1}$. Peak torque was measured using a speed-controlled isokinetic dynamometer (Cybex II, Lumex Inc., Ronkonkoma, NY) with a specially designed program which included torque comparison adjusted to the weight of the leg. The knee to be tested was positioned at $90^{\circ}$ of flexion, $\left(0^{\circ}=\right.$ fully extended knee $)$, in order to align the axis of the dynamometer lever arm with the distal point of the lateral femoral condyle. Gravity correction was performed for the tested leg. The length of the level arm was individually determined and the resistance pad placed proximal to the medial malleolus. The non-tested leg was hanging freely. Knee extension started when the knee positioned at $90^{\circ}$ of the flexion while the knee flexion started when the knee was in full extension $\left(0^{\circ}\right)$. Subjects were instructed to cross their arms over their chest and to kick the leg as hard and as fast they could through a complete range of motion. Three repetitions were carried out at each angular velocity and the best torque was used for the reanalysis. A $30 \mathrm{sec}$ rest period was taken between each trial and a $60 \mathrm{sec}$ rest period between each velocity measurement. During these procedures, subjects always performed maximal voluntary contractions, in which verbal encouragements was given to the subjects throughout the contractions. The concentric strength ratio between the knee flexors and the knee extensors ( $\mathrm{H}: \mathrm{Q}$ ratio) was expressed as the ratio between the peak values at each velocity. The conventional $\mathrm{H}: \mathrm{Q}$ ratio determined as maximal hamstrings strength divided by maximal quadriceps strength.

\section{Determination of maximum oxygen uptake}

$\dot{\mathrm{V}}_{2 \max }$ was performed on a motorised treadmill (Jaeger LE 6000, Wurzburg, Germany) after a five-minute warm-up and stretching of the lower limbs. Subjects exercised to exhaustion according to a maximal incremental continuous exercise protocol consisting of ten 1-minute stages. The initial grade and speed were set at $0 \%$ at 8 and $10 \mathrm{~km} / \mathrm{h}$, respectively, and followed by an increase in speed of $1 \mathrm{~km} / \mathrm{h}$ per stage with $2 \%$ stable grade. $\dot{\mathrm{V}} \mathrm{O}_{\text {max }}$ values and cardiorespiratory indices were measured via an ergospirometric device based on breath by breath automated pulmonary/metabolic gas exchange system (Oxycon Pro-Jaeger, Wurzburg, Germany) using a fight face mask specially designed for children. The heart rate (HR) was recorded by means of a 12-lead electrocardiogram (Viasys) connected to the ergospirometric apparatus. Subsequently, the following additional cardiorespiratory indices were determined during the test: the exercise duration; the respiratory exchange ratio (RER); the maximal heart 
rate $\left(\mathrm{HR}_{\max }\right) \cdot \mathrm{VO}_{2 \max }$ was assumed when three of the four following criteria were met: a) the HR during the last minute exceeded $95 \%$ of the expected maximal HR predicted 220-age; b) a respiratory exchange ratio $\left(\mathrm{VCO}_{2} / \mathrm{VO}_{2}\right)$ at or higher than 1.1 was reached; c) $\mathrm{VO}_{2}$ reached a plateau and/or signs of subjective exhaustion were present and were no longer to run despite verbal encouragement; d) level of concentration of blood lactate higher than $6 \mathrm{mmol}^{-1}$. Blood samples were obtained from a warmed fingertip and the concentration of blood lactate was determined in the 5th min of recovery using a lactate photometer analyser (Accusport, Boegringer Manheim, Germany).

\section{Statistical analysis}

All data are expressed as mean \pm standard deviation $( \pm$ SD). Independent sample T-test analysis was used to determine the differences among young football players and untrained boys. The statistical analysis was performed via the Statistical Package for Social Sciences (SPSS, version 22.0, Chicago, Illinois). The level of significance was set at $\mathrm{p}<0.05$.

\section{RESULTS}

The physical and anthropometric characteristics of the subjects are demonstrated in Table 1. No significant differences were found between the two groups regarding the age, height, weight, BSA and BMI. The results of the cardiorespiratory exercise testing are shown in Table $2 . \mathrm{HR}_{\max }$, resting systolic blood pressure $\left(\mathrm{sBP}_{\text {rest }}\right)$ and diastolic blood pressure $\left(\mathrm{dBp}_{\text {rest }}\right)$ showed no significant difference between the groups. However, the resting heart rate $\left(\mathrm{HR}_{\text {rest }}\right)$ was significantly lower in the trained group compared to untrained group $(\mathrm{p}<0.01)$. Moreover, the trained group presented significantly higher RER $(\mathrm{p}<0.01)$ and $\mathrm{BL}_{\text {max }}$ values $(\mathrm{p}<0.001)$. The relative peak torque values of knee extensors and knee flexors were significantly different between the two groups as presented in Figure 1. At angular velocities of $60^{\circ} \mathrm{s}^{-1}$ and $180^{\circ} \mathrm{s}^{-1}$ the trained group had significantly higher peak torque value compared to untrained group $(\mathrm{p}<0.01$ and $\mathrm{p}<0.05$ respectively). However, no significant difference was found between groups in the fast angular velocity of $300^{\circ} \mathrm{s}^{-1}$. Figure 2 shows no significant difference in absolute peak torque of the knee extensors and knee flexors between the two groups

Table 1 Physical and anthropometric characteristics of the subjects (mean \pm SD)

\begin{tabular}{lcc}
\hline & $\begin{array}{c}\text { Trained group } \\
(\mathbf{n}=20)\end{array}$ & $\begin{array}{c}\text { Untrained group } \\
(\mathbf{n}=18)\end{array}$ \\
\hline Age (years) & $14 \pm 0$ & $14 \pm 0$ \\
Experience (years) & $7 \pm 3$ & \\
Height $(\mathrm{cm})$ & $165.5 \pm 8.5$ & $168.2 \pm 10.5$ \\
Weight $(\mathrm{kg})$ & $56.9 \pm 9.5$ & $59.3 \pm 9.9$ \\
$\mathrm{BMI}\left(\mathrm{kg} \mathrm{m}^{-2}\right)$ & $20.5 \pm 2.4$ & $20.9 \pm 2.4$ \\
$\mathrm{BSA}\left(\mathrm{m}^{2}\right)$ & $1.6 \pm 0.2$ & $1.7 \pm 0.2$ \\
\hline
\end{tabular}

$B M I=$ Body Mass Index $; B S A=$ Body Surface Area 
at all angular velocities $\left(60,180,300^{\circ} \mathrm{s}^{-1}\right)$. Likewise, the $\mathrm{H} / \mathrm{Q}$ peak torque ratio did not differ between the trained and the untrained group as presented in Figure 3. In figure 4 presented the $\mathrm{VO}_{2 \max }$ in absolute $\left(\mathrm{ml} \mathrm{O}_{2} \mathrm{~min}^{-1}\right)$ and relative $\left(\mathrm{ml} \mathrm{O}_{2} \mathrm{~min}^{-1} \mathrm{~kg}^{-1}\right)$ values. The trained group showed significantly higher values in comparison with the untrained group $(\mathrm{p}<0.001)$.

Table 2 Cardiorespiratory and metabolic values of the subjects

\begin{tabular}{lcc}
\hline & $\begin{array}{c}\text { Trained group } \\
(\mathbf{n}=\mathbf{2 0})\end{array}$ & $\begin{array}{c}\text { Untrained group } \\
(\mathbf{n}=\mathbf{1 8})\end{array}$ \\
\hline $\left.\mathrm{HRrest}(\mathrm{b} \mathrm{min})^{-1}\right)$ & $65 \pm 3 * *$ & $73.1 \pm 9$ \\
$\mathrm{SBP}_{\text {rest }}(\mathrm{mmHg})$ & $112.9 \pm 5$ & $118.6 \pm 6.8$ \\
$\mathrm{dBP}_{\text {rest }}\left(\mathrm{mmHg}^{-1}\right)$ & $63.6 \pm 5.4$ & $62.2 \pm 4.3$ \\
$\mathrm{HRmax}\left(\mathrm{b} \mathrm{min}{ }^{-1}\right)$ & $197.8 \pm 4.5$ & $198 \pm 5.6$ \\
Respiratory exchange ratio (RER) & $1.2 \pm 0.2 * *$ & $1.0 \pm 0.1$ \\
BLa max $\left(\mathrm{mmoll}^{-1}\right)$ & $8.7 \pm 1.8 * * *$ & $6.4 \pm 1.2$ \\
\hline
\end{tabular}

** $p<0.01$, Trained group vs Untrained group; *** $p<0.001$, Trained group vs Untrained group
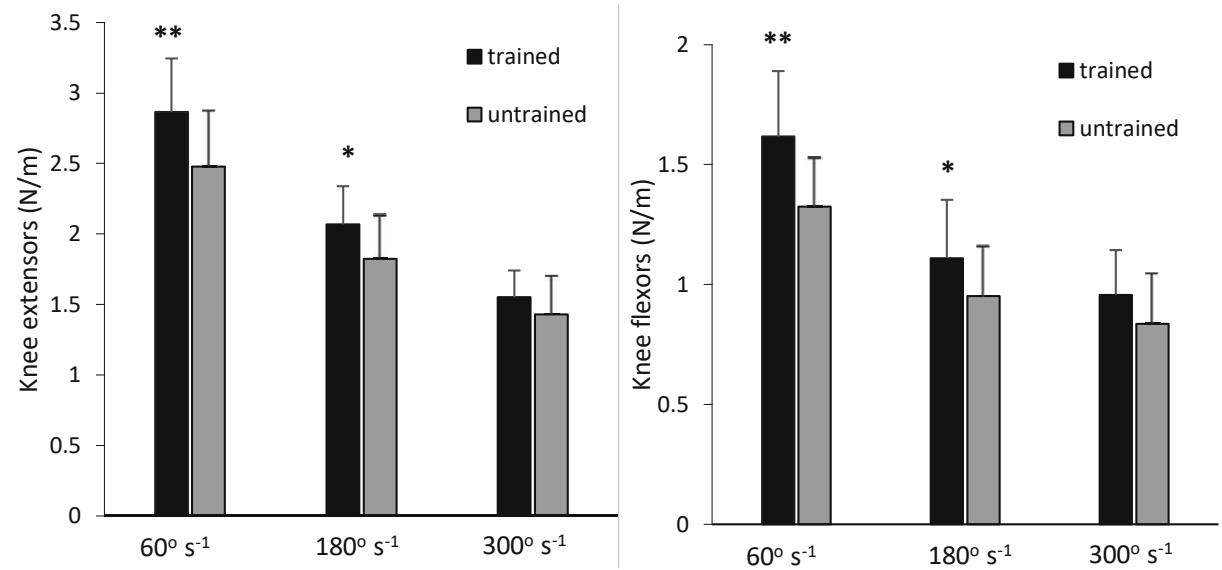

Figure 1 Relative Peak torque of knee extensors and flexors for trained and untrained group at different angular velocities. The values are expressed as means \pm SD

${ }^{*} \mathrm{p}<0.05$, Trained vs Untrained; ${ }^{* *} \mathrm{p}<0.01$, Trained vs Untrained 
27 Maximal oxygen uptake and concentric isokinetic muscle strength in pubertal football trained and untrained boys
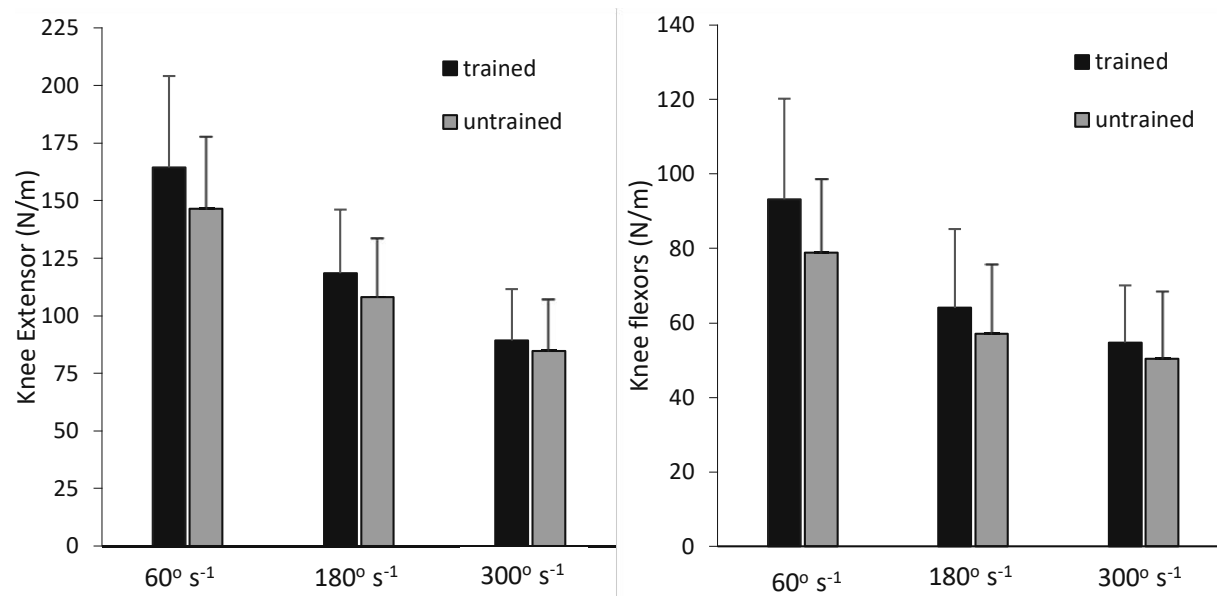

Figure 2 Absolute Peak torque of knee extensors and flexors for trained and untrained group at different angular velocities. The values are expressed as means \pm SD

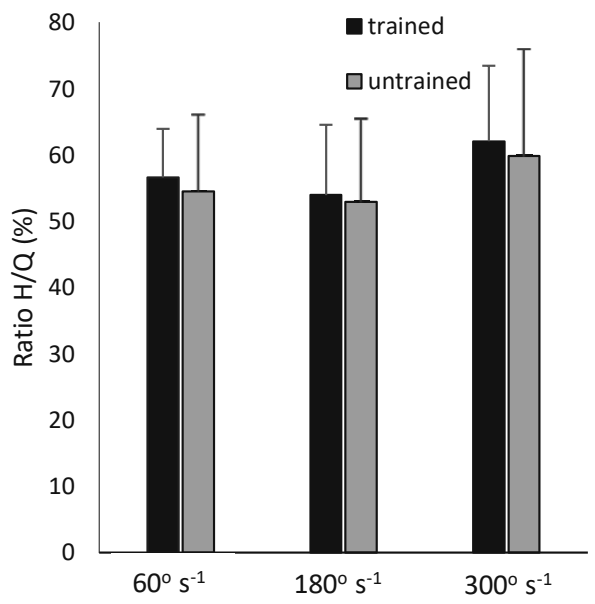

Figure 3 Peak torque rations of $\mathrm{H} / \mathrm{Q}$ at 3 angular velocities for the determination of peak torque. Values represent means $\pm S D$. $H / Q$ ratio values presented no significant differences between the groups 

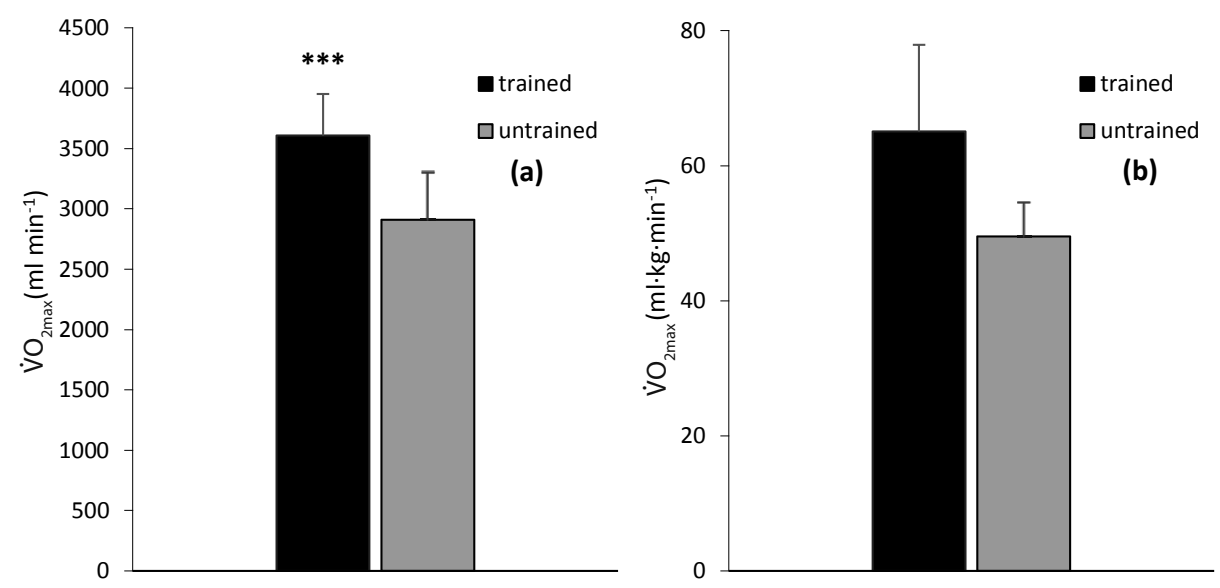

Figure 4 Absolute (a) and Relative (b) maximal aerobic power values during the maximal running test.

Values represent mean \pm SD

*** $p<0.001$, Trained vs Untrained

\section{DISCUSSION}

The purpose of this study was to examine and compare the aerobic power and the concentric isokinetic muscle strength between trained and untrained boys of the same biological age. The results of the present study showed that theVंO ${ }_{2 \max }$ both in absolute and relative values were higher in the trained group compared to untrained group. Football training during previous years has showed to have effects in aerobic power. The higher aerobic capacity that was found in the trained group may be attributed not to training only, but to hereditary endowment. In football as in all sport, young athletes constitute a highly select group chosen on the basis of size and technical skills. Football training improve the running economy, the neuromuscular function and the adaptations resulting from the higher training intensity. While significant difference were found in relative muscle peak torque, no significant difference were observed across absolute muscle strength between the two groups. The torque - velocity relationship in both groups showed a similar, adult-like pattern, namely as angular velocity increased peak torque decreased. Quadriceps strength is greater than hamstrings strength at all angular velocities. However, it is interesting to note that the absolute strength of quadriceps and hamstrings was similar in the two groups. Our results are in agreement with other studies for young football players (Berg et al., 1985; Capranica et al., 1992) who have documented no difference in isokinetic strength of the lower limbs in preadolescent boys compared to no athletes and in disagreement with all previous studies that have investigated the quadriceps and hamstrings strength in isokinetic dynamometer between groups with various chronological age. The differences in relative muscle strength were observed in slow $\left(60^{\circ} \mathrm{s}^{-1}\right)$ and moderate $\left(180^{\circ} \mathrm{s}^{-1}\right)$ angular velocities. The non-significant difference that was found at fast angular velocity of $300^{\circ} \mathrm{s}^{-1}$ may be due to the fact that boys in this age are insufficient to develop maximum torque in relation to time. It is known that in normal children the aerobic 
power, eccentric and concentric peak torque of the knee joint increase during growth and development. Blimkie (1989) suggested that a complex interaction of factors may contribute to the development of isokinetic leg strength during growth and maturation. Cross-sectional studies have indicated strong relationships between stature, body mass and isokinetic leg strength (De Ste Croix et al., 1999; Housh et al., 1995). Some studies (Alexander \& Molnar, 1973; Kanehisa et al., 1995; Pääsuke et al., 2001) showed an increase in muscle strength of quadriceps and hamstrings in untrained children during growth and developments. Children in biological age of 14 years occur during a period of transition to adolescent (adulthood) that is often viewed within the context of sexual maturation and stature growth. The biological events that occur are complex and include changes to the nervous and endocrine system (Beunen \& Malina, 1988). The trained group undergo a more systematic strength and endurance training with high frequency, intensity and durations. Despite not measuring serum testosterone in our study, our results would agree with Hansen et al. (1999) and Zakas et al. (1994) who indicated that training and age lead to hormonal and metabolic adaptations. Zakas et al. (1994) showed that training can be a stimulus for increased growth hormone and testosterone in pubertal but not in prepubertal (10 years) boys. The term muscular imbalance usually refers to the strength relationship between hamstrings to quadriceps muscles. The kinetic characteristics in football such as starting, jumping, feints and directional and speed changes place greater stress of the lower limbs. Our results showed no significant differences in $\mathrm{H}: \mathrm{Q}$ strength ratio between the groups in all angular velocities. The strength of quadriceps and hamstrings in this age seems to have a parallel increase. The data of $\mathrm{H}: \mathrm{Q}$ strength ratio produced in the present study may be useful but, at least at young ages, it is doubtful whether these data can provide a definitive answer on how to develop a tool for preventing hamstrings or quadriceps muscle injuries. It must be pointed out that the relationship of function between hamstrings and quadriceps muscles in terms of the strength and muscle balance in practice plays a key role in the movement of the knee joint, which is why it is of great interest and is given special attention both in sport medicine as well as in the rehabilitation settings. The results of the present study indicate that football training has a positive effect in metabolic capacity, cardiorespiratory system and muscle strength of the lower limbs. In summary, the results suggest that football training improved $\mathrm{VO}_{2 \max }$ and muscle strength of knee extensor and flexor muscles more than the expected increases which were attributed to age and corresponding physical growth and maturation. Our findings may have been influenced by genetic factors, the selection of young subjects for specific sport and adaptations caused by training. However, the current study could indicate further research regarding the effects of age, training and their combination on muscle strength and performance in pubertal trained and untrained boys. 


\section{ACKNOWLEDGEMENTS}

We would like to thank all participants and research support staff involved in this study for their committed participation. No external financial support was received for this investigation.

\section{REFERENCES}

Alexander, J., \& Molnar, G. E. (1973). Muscular strength in children: preliminary report on objective standards. Archives of Physical Medicine and Rehabilitation, 54(9), 424-427.

Armstrong, N. (1997). Young people and physical activity. Oxford University Press, USA.

Bar-Or, O. (1983). Physiologic responses to exercise of the healthy child. In: Pediatric Sports Medicine for the Practitioner (pp. 1-65). New York, NY: Springer.

Baxter-Jones, A., Goldstein, H., \& Helms, P. (1993). The development of aerobic power in young athletes. Journal of Applied Physiology, 75(3), 1160-1167.

Berg, K. E., LaVoie, J. C., \& Latin, R. W. (1985). Physiological training effects of playing youth soccer. Medicine and Science in Sports and Exercise, 17(6), 656-660.

Beunen, G., \& Malina, R. M. (1988). Growth and physical performance relative to the timing of the adolescent spurt. In: Pandolf, K. B. (Ed.), Exercise and Sport Sciences Reviews, 16(1), 503-540. New York: Mcmillan Publishing Company.

Blimkie, C. J., Ebbesen, B., MacDougall, D., Bar-Or, O., \& Sale, D. (1989). Voluntary and electrically evoked strength characteristics of obese and nonobese preadolescent boys. Human Biology, Aug 1, 515-532.

Capranica, L., Cama, G., Fanton, F., Tessitore, A., \& Figura, F. (1992). Force and power of preferred and non-preferred leg in young soccer players. The Journal of Sports Medicine and Physical Fitness, 32(4), 358-363.

De Ste Croix, M. B. A., Armstrong, N., \& Weisman, J. R. (1999). Concentric isokinetic leg strength in pre-teen, teenage and adult males and females. Biology of Sport, 16(2), 75-86.

Eriksson, B. O., \& Koch, G. (1973). Effect of physical training on hemodynamic response during submaximal and maximal exercise in 11-13-year old boys. Acta Physiologica Scandinavica, 87(1), 27-39.

Hagger, M. S., Chatzisarantis, N., \& Biddle, S. J. (2001). The influence of self-efficacy and past behaviour on the physical activity intentions of young people. Journal of Sports Sciences, 19(9), 711-725.

Hansen, L., Bangsbo, J., Twisk, J., \& Klausen, K. (1999). Development of muscle strength in relation to training level and testosterone in young male soccer players. Journal of Applied Physiology, 87(3), 1141-1147.

Housh, D. J., Housh, T. J., Weir, J. P., Weir, L. L., Johnson, G. O., \& Stout, J. R. (1995). Anthropometric estimation of thigh muscle cross-sectional area. Medicine \& Science in Sports and Exercise, 27(5), 784-791.

Kanehisa, H., Yata, H., Ikegawa, S., \& Fukunaga, T. (1995). A cross-sectional study of the size and strength of the lower leg muscles during growth. European Journal of Applied Physiology and Occupational Physiology, 72(1-2), 150-156.

Kobayashi, K., Kitamura, K. I., Miura, M. O., Sodeyama, H. I., Murase, Y. U., Miyashita, M. I., \& Matsui, H. I. (1978). Aerobic power as related to body growth and training in Japanese boys: a longitudinal study. Journal of Applied Physiology, 44(5), 666-672.

Krustrup, P., Dvorak, J., Junge, A., \& Bangsbo, J. (2010). Executive summary: The health and fitness benefits of regular participation in small-sided football games. Scandinavian Journal of Medicine \& Science in Sports, 20(s1), 132-135. 
Lussier, L., \& Buskirk, E. R. (1977). Effects of an endurance training regimen on assessment of work capacity in prepubertal children. Annals of the New York Academy of Sciences, 301(1), 734-747.

Máček, M., Vavra, J., \& Novosadova, J. (1976). Prolonged exercise in prepubertal boys. European journal of Applied Physiology and Occupational Physiology, 35(4), 291-298.

Malina, R. M., Eisenmann, J. C., Cumming, S. P., Ribeiro, B., \& Aroso, J. (2004). Maturity-associated variation in the growth and functional capacities of youth football (soccer) players 13-15 years. European Journal of Applied Physiology, 91(5-6), 555-562.

Mandroukas, A., Vamvakoudis, E., Metaxas, T., Papadopoulos, P., Kotoglou, K., Stefanidis, P., \& Mandroukas, K. (2014). Acute partial passive stretching increases range of motion and muscle strength. The Journal of Sports Medicine and Physical Fitness, 54(3), 289-297.

Mirwald, R. L., \& Bailey, D. A. (1984). Longitudinal comparison of aerobic power and heart rate responses at submaximal and maximal workloads in active and inactive boys aged 8 to 16 years. In: Human Growth and Development. Borms, J., Hauspie, J., Sand, A., Suzanne, C., \& Hebbelinck, M. (Eds.), pp. 561-569. New York: Plenum.

Mirwald, R. L., Bailey, D. A., Cameron, N., \& Rasmussen, R. L. (1981). Longitudinal comparison of aerobic power in active and inactive boys aged 7.0 to $17 \cdot 0$ years. Annals of Human Biology, 8(5), 405-414.

Nadeau, K. J., Maahs, D. M., Daniels, S. R., \& Eckel, R. H. (2011). Childhood obesity and cardiovascular disease: links and prevention strategies. Nature Reviews Cardiology, 8(9), 513-525.

Pääsuke, M., Ereline, J., \& Gapeyeva, H. (2001). Knee extensor muscle strength and vertical jumping performance characteristics in pre-and post-pubertal boys. Pediatric Exercise Science, 13(1), 60-69.

Savage, M. P., Petratis, M. M., Thomson, W. H., Berg, K., Smith, J. L., \& Sady, S. P. (1986). Exercise training effects on serum lipids of prepubescent boys and adult men. Medicine and Science in Sports and Exercise, 18(2), 197-204.

Tanner, J. M. (1962). Growth at Adolescence. 2nd ed. Oxford: Blackwell Scientific Publications.

Vamvakoudis, E., Dalkiranis, A., Vrabas, I. S., Christoulas, K., \& Mandroukas, K. (2001). The effects of physical training on the basic components of physical fitness in pubertal boys. Journal of Human Movement Studies, 41(3), 209-224.

Vamvakoudis, E., Vrabas, I. S., Galazoulas, C., Stefanidis, P., Metaxas, T. I., \& Mandroukas, K. (2007). Effects of basketball training on maximal oxygen uptake, muscle strength, and joint mobility in young basketball players. The Journal of Strength \& Conditioning Research, 21(3), 930-936.

Williams, A. M., \& Reilly, T. (2000). Talent identification and development in soccer. Journal of Sports Sciences, 18(9), 657-667.

Zakas, A., Mandroukas, K., Karamouzis, G., \& Panagiotopoulou, G. (1994). Physical training, growth hormone and testosterone levels and blood pressure in prepubertal, pubertal and adolescent boys. Scandinavian Journal of Medicine \& Science in Sports, 4(2), 113-118. 